\title{
Somatic Embryo Formation and Plant Regeneration in 'Zaoh' line No.2 of Japanese Angelica Tree (Aralia elata seem.)
}

\author{
Keiichi AMEMIYA* and Tohru Mochizuki \\ Yamanashi Agricultural Research Center, Futaba, Kitakoma, Yamanashi 405-0105, Japan \\ *Corresponding author E-mail address: VEQ03365@nifty.ne.jp
}

Received 2 July 2002 ; accepted 10 September 2002

\begin{abstract}
Mass propagation of the Japanese angelica tree (Aralia elata seem.) 'Zaoh' line No.2 was established through somatic embryos. Petioles of leaflets were cultured for induction of calli on an MS medium containing $1 \mathrm{mg}^{-1}$ of $2,4-\mathrm{D}$ in combination with $0.5 \mathrm{mg}^{-1} \mathrm{BA}$. The initiated calli were moved onto MS medium supplemented with glutamine $450 \mathrm{mg} \mathrm{l}^{-1}$ and asparagine $300 \mathrm{mg} \mathrm{l}^{-1}$. An embryogenic callus developed after 5 months and was moved onto regulator-free MS medium. Numerous plantlets were regenerated from this embryogenetic callus, and rooted plantlets were potted after acclimation and planted to the field. The plants had the same characteristics in morphology in the field, except for the number of thorns per internode. The plants also had the same resistance to Phytophthora disease as was in the original genotype 'Zaoh' line No.2. This study provided a method for mass propagation from petioles of leaflets and proves that regenerated plants maintain the morphogenetic characteristics and disease resistance of the original genotype.
\end{abstract}

Key words: Araria elata seem., embryogenetic callus, Japanese angelica tree, mass propagation, somatic embryo.

\section{Introduction}

Araria elata seem, commonly called the Japanese angelica tree, is one of the most popular species native to our country ; in addition, there are some districts in our Yamanashi prefecture cultivating the shrub in the field. Some commercial lines of landscape cultivars have been developed. We selected 2 distinctive lines, 'Koma-Midori' and 'Shin-Koma', from a line growing locally in the mountains and shared these lines with farmers in our area. The 'Koma-Midori' line has larger terminal buds and a smaller number of thorns than the local line, and the 'Shin-Koma' line has larger lateral buds than 'Koma-Midori'. However, both commercial lines had no resistance to Phytophthora disease (Phytophythora cactorum) (Ichikawa et al, 1989, 1993), and were severely damaged by this fungal disease in our prefecture. Phytophthora is known for spreading by soil contamination and easily entering via wounds. This poses a special problem for the Japanese angelica tree, which is generally propagated by root cuttings in early spring: the wound to the roots affects both the mother plant and the clonal progeny, making them extremely vulnerable to the inva- sion by this disease.

Propagation by tissue cultures of embryogenetic callus is one of the best alternative methods for protection against this disease. It also has the advantage of year-round propagation. For the propagation of the local lines, 'Koma-Midori 'and 'Shin-Koma', we established a mass propagation method using tissue cultures derived from embryogenetic calli (Amemiya et al., 1992). Another commercial line, 'Zaoh', had shown resistance to this disease; however, it had not been established by propagation through embryogenic calli. Thus, it was necessary to establish its propagation through embryogenic callus and determine whether regenerated plants maintained a resistance to the disease. The present study was carried out to determine optimal conditions for embryogenic callus induction, and to investigate the characteristics of regenerated plants in the field.

\section{Materials and Methods}

Japanese angelica tree 'Zaoh' line No.2 (Aralia elata seem.) was selected as a disease--resistant line native to the Yamagata prefecture. Seedlings were kindly provided from the local government of 
Yamagata and planted to a field at High Land Branch of Yamanashi Agricultural Research Center, Japan. Petioles of plants grown in the field were sampled after budding in early April. The leaflet petioles were washed with running tap water for 5 min and then moved to a clean bench.

The leaflet petioles were cut into $1 \mathrm{~cm}$ sections and immersed for a few seconds in $70 \%$ ethanol, after which they were sterilized in $0.1 \%$ sodium hypochlorite solution for $10 \mathrm{~min}$. and finally rinsed thoroughly with sterile, distilled water under aseptic conditions. For callus induction, the explants were then placed onto an MS medium (Murashige et al. 1962) supplemented with $1 \mathrm{mg} 2,4$-dichorophenoxyacetic acid $(2,4-\mathrm{D}), 0.1 \mathrm{mg} 1^{-1} \mathrm{~N}^{6}$ - benzylaminopurine(BA) at various concentrations, $30 \mathrm{gl}^{-1}$ sucrose, and $8 \mathrm{~g}^{-1}$ agar. The $\mathrm{pH}$ of the MS medium was adjusted to 5.6 prior to autoclaving at $115^{\circ} \mathrm{C}$ for $15 \mathrm{~min}$. The $500 \mathrm{ml}$ conical beakers containing $100 \mathrm{ml}$ of medium were capped with aluminum foil ; each treatment consisted of 18 or 23 flasks with 5 calli per flask. The entire experiment was repeated 3 times. Callus formation was observed after 1 month. Calli were separated from explants, then moved onto MS medium solidified with $8 \mathrm{~g} \mathrm{l}^{-1}$ agar and supplemented with glutamine, asparagine, glutamic acid, aspartic acid, and $30 \mathrm{~g}^{-1}$ sucrose. Five months later, a single embryogenic callus developed. The embryogenic callus was separated from the original callus, then moved onto basal MS medium solidified with $8 \%$ agar for regeneration. All cultures were kept at $25^{\circ} \mathrm{C}$ under continuous lighting with cool white fluorescent lamps at 3,000 $5500 \mathrm{~lx}$. Shoots and roots were regenerated from the embryogenic callus after several days. The rooted plants were transplanted to

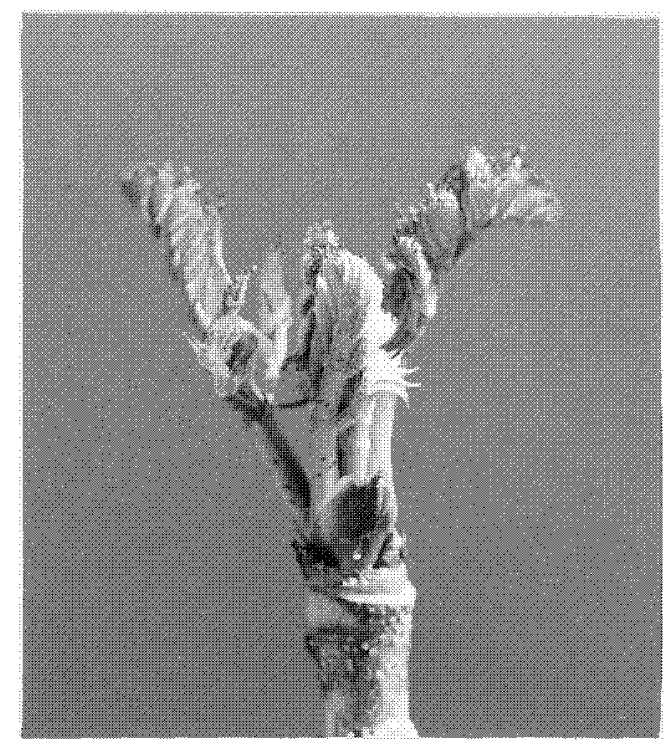

Fig. 1 Newly bud of Japanese angelica tree 'Zaoh' line No. 2 in early spring vermiculite in a clear polyethelene vessel and covered with a polyester clear lid to keep full humidity. As the plants gained in vigor, the container covers were poked by a gimlet to allow air to enter the container until plants were self-supported. The plants were potted in seedling soil after 3 weeks and cultivated in the greenhouse. After one month they were planted to the field and cultivated for 10 months.

To examine field resistance, $1 \mathrm{~cm}$ diameter of roots from the regenerated plants were cut into 15 $\mathrm{cm}$ sections and disinfected by Benlate (benomyl) at a dilution rate of 2,000 to 1 . The roots were planted to the field on April 22, 1998. One set of roots was used for investigating morphological characteristics; there were 30 plants at this plot. Other roots were planted at an infected field in order to investigate disease resistance in comparison with the control plant, 'Shin-Koma'. There were 42 plants at the infected plot. Growth characteristics at each plot were investigated from May to October, 1998.

\section{Results and Discussion}

Newly terminal buds in early spring have limited contamination with sundry germs, making them suitable material for tissue cultures (Fig. 1). The optimum part of the bud for callus induction by tissue culture was the petiole of leaflets. The optimum concentration of BA on the medium was 0.1 or $0.5 \mathrm{mg} \mathrm{l}^{-1}$ under $1.0 \mathrm{mg}^{-1} 2,4-\mathrm{D}$. This result was similar to our experience with the Japanese angelica tree, 'Shin-Koma' (Amemiya et al., 1992), (Table 1).

It has been reported that the amount and form of nitrogen was critical for somatic embryogenesis in asparagus (Yang et al., 2000). In general, the addition of nutritive substances to the culture medium was the key factor for induction of somatic embryogenesis, especially reductive nitrogen such as am-

Table 1. Concentration of $\mathrm{N}^{6}$ - benzylaminopurine(BA) and callus formation

\begin{tabular}{cccc}
\hline $\begin{array}{c}\text { Concentration No. of placed } \\
\text { of BA } \\
\left(\mathrm{mg} \mathrm{l}^{-1}\right)^{1)}\end{array}$ & $\begin{array}{c}\text { No. of callus } \\
\text { pectiode }\end{array}$ & $\begin{array}{c}\text { amount of } \\
\text { formated } \\
\text { section }(\%)\end{array}$ & $\begin{array}{c}\text { callus } \\
\text { formation }\end{array}$ \\
\hline 0.05 & 100 & $86(86)$ & ++ \\
0.1 & 100 & $92(86)$ & +++ \\
0.5 & 20 & $19(95)$ & +++ \\
\hline${ }^{13}$ medium : MS $+2,4-\mathrm{D} 1 \mathrm{mg} \mathrm{l}^{-1}$ & \\
${ }^{23}$ amount of callus formation; + under $2 \mathrm{~mm}$ \\
diameter, ++ \\
mm diameter
\end{tabular}


Table 2. Effect of glutamine (Gln) and asparagine (Asn) on embryogenetic callus induction from callus of Japanese Angelica Tree (after 5 months from replacing )

\begin{tabular}{|c|c|c|}
\hline Kind of addition and amount ${ }^{1)}$ & Ratio of suvival callus & $\%$ of embyogenetic induction \\
\hline Gln $450 \mathrm{mg} \mathrm{l}^{-1}$ & $22.2 \%$ & $(0 / 90)^{3)}$ \\
\hline Asn $300 \mathrm{mg} \mathrm{l}^{-1}$ & 7.8 & $(0 / 90)$ \\
\hline \multirow[t]{2}{*}{$\operatorname{Gln} 450 \mathrm{mg} \mathrm{l}^{-1}+\operatorname{Asn} 300 \mathrm{mg} \mathrm{l}^{-12)}$} & 6.7 & $1.1(1 / 90)$ \\
\hline & 6.1 & $0.9 \quad(1 / 115)$ \\
\hline 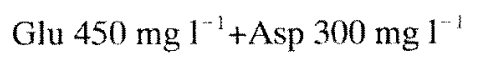 & 24.4 & $(0 / 90)$ \\
\hline
\end{tabular}

"Gln: glutamine, Asn: asparagine, Glu: gultamic acid, Asp: aspartic acid

${ }^{23}$ the exeperiments were repeated twice.

${ }^{3)}$ (number of embyogenetic induction / number of placed callus)

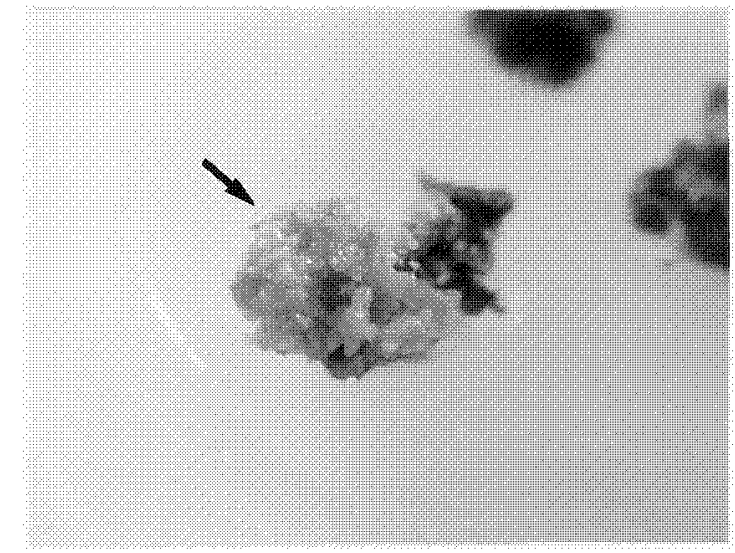

Fig. 2 Embryogenetic callus formation in Angelica tree 'Zaoh' line No.2

moniac nitrogen. Nitrogen compounds added to the medium promote nitrogen metabolism activity, cell division, and ultimately, somatic embryogenesis (Kamada, 1996). Glutamine is one of reductive nitrogen and well known that glutamine and asparagine participate in the induction of somatic embryo calli on some plants (Kamada, 1996).

In the present study, embryogenic calli were induced on a medium including glutamine $450 \mathrm{mg}$ $1^{-1}$ and asparagine $300 \mathrm{mgl}^{-1}$ (Table 2, Fig. 2). Embryogenesis was synchronous for those calli that quickly propagated regenerated plants and reproducibility was nonetheless confirmed. The rate of induction, however, was small $(1.1 \%$ and $0.9 \%)$. Thus, it was considered that glutamine was the important factor for inducing embryogenetic callus.

On the other hand, stress was also important for inducing somatic embryogenetic calli. It has been reported that in carrots, somatic embryogenesis was induced by treatments of apical tip segments with high concentrations of sucrose, $\mathrm{NaCl}$ or heavy metal ions. Other stress factors known to induce somatic embryos, include heat, high pressure, high temperature, high concentration of plant hormones and so on (Kamada, 1996). Stress-induced changes in protein patterns and the proteins associated with stress-induced somatic embryogenesis in carrots have been investigated, along with several proteins commonly detected in relation to the induction of somatic embryogenesis in other organisms (Tachikawa et al., 1998).

In this case, it seems that glutamin and asparagine were stress factors in the induction of calli in the 'Zaoh' line, as a result of influence on nitorgen metabolism.

Somatic embryogenesis has been established from leaf disks and immature seeds in Udo (Aralia cordata thunb.), a plant belonging to the same genus as the Japanese angelica tree (Nishihira et al., 1998). Optimal conditions for inducing somatic embryogenesis in Udo has proven different for each line. In fact, it is well known that optimal conditions for somatic emgryogenesis differ considerably within a genus, family, or line : for example, carrots, soybeans, alfalfa and so on (Kamada, 1996; Nishihira et al., 1998). In this study, 2 kinds of amino acids were the main stimulants in the 'Zaoh' line, while the concentration of Fe-EDTA in the MS medium was the main stimulant in 'Shin-Koma' and other several lines (Amemiya et al., 1992). It seems that one of the reasons that the line of 'Zaoh' differs from 'Koma-Midori', 'Shin-Koma', and the generalized local line in our prefecture is that their original habitats are different from each other.

The results showed that an MS medium supplemented with glutamine and asparagine can establish embryogenic calli over a relatively long term(5 months) culture. And it was also suggested that both animo acids could contribute to inducing embryogenic calli.

Unfortunately, the rate of embryogenesis in this culture was quite low in the 'Zaoh' line in comparison with the other lines (Amemiya et al., 1992; Koyama, 1992; Haraguchi, 1993), but the reproducibility was nonetheless recognized. Furthermore, the embryogenic calli were able to propagate quickly, 
Table 3. Comparison of morphology on cultured plants with original genotype

\begin{tabular}{lcc}
\hline \multicolumn{1}{c}{ Investigated item } & Cultured seedlings & Original genotype \\
\hline plant length & $1.13 \mathrm{~m}$ & $1.14 \mathrm{~m}$ \\
No. of node & 21.7 sheets & 21.4 sheets \\
length of internode & $8.0 \mathrm{~cm}$ & $7.1 \mathrm{~cm}$ \\
(between 10th node and 11th node) & & \\
thorn of leaf & exist & exsil \\
No. of thron per internode & 4.0 & 8.1 \\
\hline
\end{tabular}

Number of investigated individual was 30 plants per each plot

Table 4. Comparison of cultured plants with original genotype on resistance to Phytophthora disease

\begin{tabular}{|c|c|c|c|c|c|c|c|c|}
\hline \multirow{2}{*}{ name of line } & \multirow{2}{*}{$\begin{array}{l}\text { No. of planted } \\
\text { roots }\end{array}$} & \multirow{2}{*}{$\begin{array}{l}\text { No. of buded } \\
\text { plants }\end{array}$} & \multicolumn{5}{|c|}{ ratio of infected stock $(\%)$} & \multirow{2}{*}{$\begin{array}{c}\text { No. of final surviving } \\
\text { explants }(\%)\end{array}$} \\
\hline & & & Jun. & Jul. & Aug. & Sep. & Oct. & \\
\hline 'Zaoh' No.2 & & & & & & & & \\
\hline (regenerated plants) & 42 & 40 & 0 & 35.0 & 67.5 & 67.5 & 67.5 & $13(31)$ \\
\hline $\begin{array}{l}\text { 'Zaoh' No.2 } \\
\text { (original genotype) }\end{array}$ & 42 & 40 & 0 & 30.0 & 62.5 & 65.0 & 65.0 & $14(33)$ \\
\hline $\begin{array}{l}\text { 'Shin-Koma' } \\
\text { (control) }\end{array}$ & 42 & 36 & 0 & 72.2 & 83.3 & 83.3 & 83.3 & $6(14)$ \\
\hline
\end{tabular}

1) ratio of infected stock $=\frac{\text { No. of withered plants }}{\text { No. of buded plants }} \times 100$

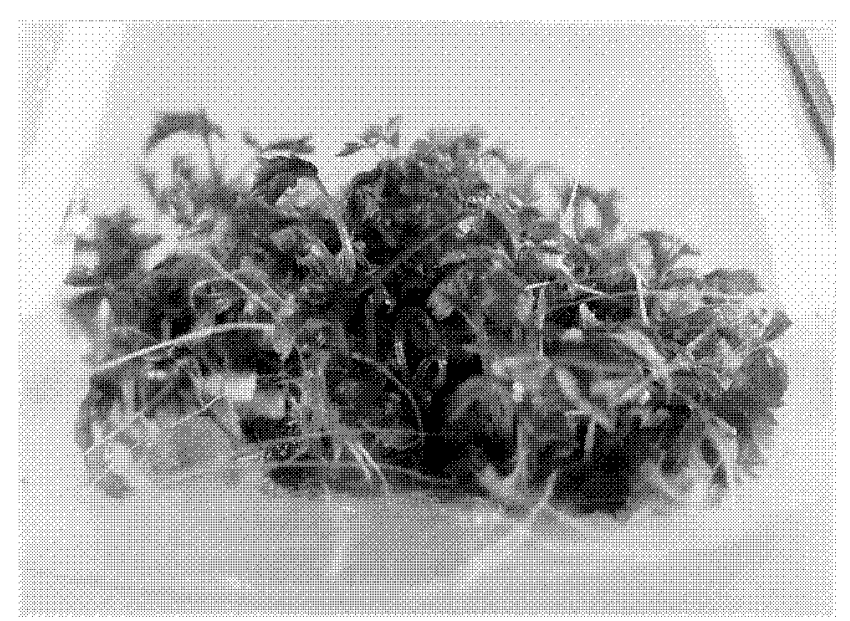

Fig. 3 Regenerating plants from embryogenetic callus in Angelica tree

and sufficed for propagating the seedlings, even though there was only one embryogenic callus.

For asparagus somatic embryogenesis, an MS liquid medium was the optimal medium, with rates of up to $80 \%$ of culture cells developed into somatic embryos in liquid medium (Yang et al., 2000). It is well known that a cell suspension culture is able to induce embryogenic calli on some plants like carrots (Nomura, 1994), cucumbers (Tabei et al., 1995), roses (Visessuwan et al., 1997), asparagus (Yang et al., 2000) and so on. Culturing cells of the
Japanese angelica tree through callus in a liquid medium has yet to be examined, but in general its cells have not demonstrated good growth in liquid media (not published the date). It seems that the rate of inducing embryogenetic calli should be high if the suspension culture is successful. Thus, it is important for angelica tree propagation to establish a suspension culture.

When embryogenic calli were placed in MS basal media, they produced many regenerated plants (Fig. 3). After being transplanted to pots, the regenerated seedlings were planted in the field and allowed to grow for 10 months, when root cuttings were taken and planted in the infected field. Morphological characteristics were mostly identical except the number of thorns per internode (Table 3): the number of thorns in regenerated plants was half of that of the original genotype plants. It is known that the number of thorns varied in regenerated plants from the other local lines (Haraguchi, 1993). The rate of infection in regenerated plants grown in the Phytophthora-infected field was similar to that of the original genotype (Table 4). The results confirmed that regenerated plants demonstrate most of the characteristics as the original genotype. The study also suggested that our technique was practical for mass propagation of seedlings of the Angelica tree; the induction efficiency was low but 
acceptable for practical use because the rate of propagation is so high.

\section{References}

Amemiya, K., Fujiki, T., Hyuga, S., 1992. Micropropagation in Japanese Angelica Tree by tissue culture. Yamanashi Agri. Rec. Cen., 5: 11 - 22. (in Japanese).

Ichikawa, K., Ono, M., 1989. Effect of temperature conditions on the disease development of Phytothora root rot of Japanese angelica tree. Kanto-Tousan Plant Prote. Soc., 36: $99-100$. (in Japanese)

Ichikawa, K., Murakami, Y., Tsutiya, S.,1993. Control effect of selection and chemical treatment of root segments of Japanese angelica tree on the infection of Phytophthora rot. Kanto-- Tousan Plant Prote. Soc., 40: 117-118.(in Japanese)

Haraguchi, M., 1993. Somatic embryogenesis from leaf and petiole tissues in Araria elata and characteristics of regenerated plants in a field. J. For. Res., 104: 601 602. (in Japanese)

Kamada, H., 1996. Physiological and molecular biological studies on somatic embryogenesis. Chemical Regulation of Plants, 31: 1-11. (in Japanese)

Koyama, M., 1992. Tissue culture in Japanese Angelica Tree (Araria elata). J. For. Breed, 163: 4- 8.(in Japanese)
Murashige, T., Skoog, F., 1962. A revised medium for rapid growth and bioasseay with tabacco tissue cultures. Physiol. Plant., 15: 473-497.

Nishihira, T., Hayashi, Y., Matsumoto, K., 1998. Somatic Embryogenesis from Leaf Disks and Immature Seeds of Aralia cordata Thunb. J. Japan Soc. Hort. Sci., 67: 81 86. (in Japanese).

Nomura, K.,1994. Mechanisms of Somatic Embryogenesis., Saiboh Kohgaku., 13 : 130-138.(in Japanese)

Tachikawa, Y., Saitou, T., Kamada, H.,Harada, H., 1998. Changes in Protein Pattern during Stress-induction of Carrot (Daucus carota L.) Somatic Embryogenesis. Plant Biotechnol, 15: 17- 22.

Tabei, Y., Seino, E., Nishimura, S., 1995. Liquid Culture and Short Induction Period Enhanced Somatic Embryogenesis in Cucumber (Cucumis sativus L.), Plant Tissue Culture Letters, 12: $79-83$.

Visesseuwan, R., Kawai, T., Mii, M., 1997. Plant Regeneration from Cell Suspension Culture Derived from Immature Embryo of Rose., Plant Biotechnol., 14: 29 33.

Yang, H., Cheng, J., Kamada, H., 2000. Moltiple Pathways of Somatic Embryogenesis at a High Frequency in Asparagus officinalis L., Plant Biotechnol, 17: 111118. 